Environmental Pollution

November 2018, Volume 242, Part A, Pages 614-625

http://dx.doi.org/10.1016/i.envpol.2018.07.023

http://archimer.ifremer.fr/doc/00449/56082/

(c) 2018 Elsevier Ltd. All rights reserved.

\title{
Microplastic bacterial communities in the Bay of Brest: Influence of polymer type and size
}

\author{
Frère Laura ${ }^{1}$, Maignien Lois ${ }^{2}$, Chalopin Morgane ${ }^{3}$, Huvet Arnaud ${ }^{3}$, Rinnert Emmanuel ${ }^{4}$, \\ Morrison Hilary ${ }^{5}$, Kerninon Sandrine ${ }^{6}$, Cassone Anne-Laure ${ }^{1}$, Lambert Christophe ${ }^{1}$, Reveillaud Julie ${ }^{7}$, \\ Paul-Pont lka ${ }^{1, *}$
}

${ }^{1}$ Laboratoire des Sciences de l'Environnement Marin (LEMAR), UMR 6539 CNRS/UBO/IRD/IFREMER

- Institut Universitaire Européen de la Mer, Technopôle Brest-Iroise - Rue Dumont d'Urville, 29280

Plouzané, France

${ }^{2}$ Laboratoire de Microbiologie des Environnements Extrêmes (LM2E), UMR 6197

IFREMER/UBO/CNRS - Institut Universitaire Européen de la Mer, Technopôle Brest-Iroise - Rue

Dumont d'Urville, 29280 Plouzané, France

${ }^{3}$ Ifremer, Laboratoire des Sciences de l'Environnement Marin (LEMAR), UMR 6539

(UBO/CNRS/IRD/Ifremer), Centre Bretagne - CS 10070, 29280 Plouzané, France

${ }^{4}$ Ifremer, Laboratoire Détection, Capteurs, Mesures (RDT-LDCM), Centre Bretagne - ZI de la Pointe du

Diable - CS 10070, 29280 Plouzané, France

5 Josephine Bay Paul Centre for Molecular Biology and Evolution, Marine Biological Laboratory, 7 MBL

Street Woods Hole, MA, United States

${ }^{6}$ LABOCEA, 22, Ave. de la Plage des Gueux, ZA de Creac'h Gwen, CS 13031, 29334 QUIMPER

Cedex, France

${ }^{7}$ ASTRE, INRA, CIRAD, University of Montpellier, Montpellier, France

*Corresponding author : Ika Paul-Pont, email address : ika.paulpont@univ-brest.fr

\begin{abstract}
:
Microplastics $(<5 \mathrm{~mm})$ exhibit intrinsic features such as density, hydrophobic surface, or high surface/volume ratio, that are known to promote microbial colonization and biofilm formation in marine ecosystems. Yet, a relatively low number of studies have investigated the nature of microplastic associated bacterial communities in coastal ecosystems and the potential factors influencing their composition and structure. Here, we characterized microplastics collected in the Bay of Brest by manual sorting followed by Raman spectroscopy and studied their associated bacterial assemblages using $16 \mathrm{~S}$ amplicon high-throughput sequencing. Our methodology allowed discriminating polymer type (polyethylene, polypropylene and polystyrene) within small size ranges (0.3-1 vs. 1-2 vs. 2-5 mm) of microplastics collected. Data showed high species richness and diversity on microplastics compared to surrounding seawater samples encompassing both free living and particle attached bacteria. Even though a high proportion of operational taxonomic units (OTU; $94 \pm 4 \%$ ) was shared among all plastic polymers, polystyrene fragments exhibited distinct bacterial assemblages as compared to polyethylene and polypropylene samples. No effect of microplastic size was revealed regardless of polymer type, site and date of collection. The Vibrio genus was commonly detected in the microplastic fraction and specific PCR were performed to determine the presence of potentially pathogenic Vibrio strains (namely $V$. aestuarianus and the $V$. splendidus polyphyletic group). $V$. splendidus related species harboring
\end{abstract}


putative oyster pathogens were detected on most microplastic pools $(77 \%)$ emphasizing the need of further research to understand the role of microplastics on pathogen population transport and ultimate disease emergence.

\section{Graphical abstract}

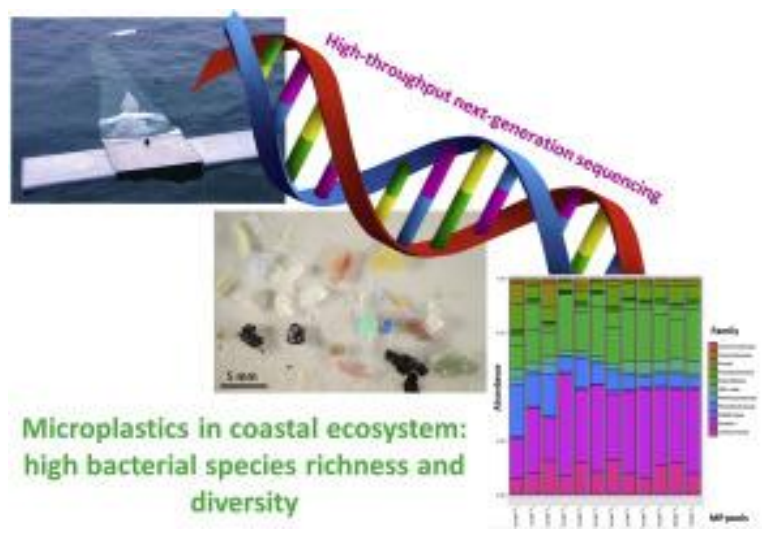

\section{Highlights}

- Study of marine microplastic bacterial communities using next-generation sequencing. High species richness and diversity was observed on microplastics. No effect of microplastic size was shown on alpha and beta diversities. Polystyrene showed different bacterial communities than polyethylene and propylene. Vibrios harboring putative oyster pathogens were detected on most microplastics.

Keywords : Bacteria, Microplastics, Coastal ecosystem, Metabarcoding, Vibrios 


\section{Introduction}

Plastic debris, and notably microplastics (defined as plastic particles $<5 \mathrm{~mm}$ (Arthur et al., 2009) contaminate the worldwide marine ecosystems (Eriksen et al., 2014; Lusher, 2015; Sebille et al., 2015) leading to increased concerns about their ecological impacts (Rochman, 2016). Owing to their global distribution and small size, microplastics are efficiently ingested by a wide range of marine organisms, from zooplankton (Cole et al., 2011) to mollusks (Van Cauwenberghe and Janssen, 2014), fishes (Foekema et al., 2013) and even marine mammals (Fossi et al., 2012) making their way into all marine food chains and posing a critical threat to marine organisms. Besides direct physical impacts upon microplastics ingestion (Wright et al., 2013) and indirect toxicity related to the release of chemicals carried by microplastics (plasticizers, pigments, monomers, adsorbed pollutants) (Koelmans et al., 2014, 2016), concerns are raising regarding the potential for microplastics to represent new substrates for microorganisms, especially harmful and pathogenic ones (Kirstein et al., 2016; Lusher, 2015; Maso et al., 2003).

The first mention of plastic debris being colonised by microorganisms (for instance diatoms and bacteria) was done by Carpenter et al. (1972). For the past decade several field studies have demonstrated that plastic debris and microplastics represent a novel substrate for habitat and transport of a wide range of marine organisms. Microplastic-associated rafting communities were observed to be composed of macrobenthic organisms such as arthropods, mollusks, bryozoans and cnidarians (Bryant et al., 2016; Goldstein et al., 2014) and eukaryotic microorganisms such as dinoflagellates, diatoms, invertebrate eggs and fungus (Maso et al., 2003; Oberbeckmann et al., 2014; Reisser et al., 2014); thus raising question about the transfer of potentially invasive rafting taxa to pristine ecosystems (Galgani et al., 2013). Dispersal of non-indigenous species through attachment to natural substrate (wood, vegetal, pumice) has been widely described (Jokiel, 1990), however the buoyant, persistent and ubiquitous nature of microplastics may significantly exacerbate the survival and longdistance transport of various hitchhikers. A recent example of this enhanced dispersal of organisms by plastic debris is the identification of nearly 300 Japanese species (mainly invertebrate) that reached the U.S. Pacific Northwest shores as a consequence of the 2011 East Japan earthquake and tsunami. Interestingly, most species were attached to the remains of manmade debris primarily composed by plastics (Carlton et al., 2017). Colonization of plastic debris and microplastics by prokaryotes has also been shown in various environments from freshwater to seawater, marine sediments and beaches (reviewed in Oberbeckmann et 
al., 2015). All these studies demonstrated a high diversity and richness of microorganisms colonizing microplastics, constituting a unique marine environment called the "Plastisphere" (Zettler et al., 2013). In addition, bacterial families harboring well-known human, fish and shellfish pathogenic strains (Vibrionaceae, Campylobacteraceae, Flavobacteriaceae and Aeromonadaceae) have been regularly detected on microplastics (Dussud et al., 2018; Kirstein et al., 2016; Schmidt et al., 2014; Viršek et al., 2017; Zettler et al., 2013). As a consequence, more research to understand the spatiotemporal patterns of plastic colonizing microorganisms and the ecological risks for marine ecosystems, food safety and public health is needed (GESAMP, 2016; Harrison et al., 2011; Keswani et al., 2016).

The aim of the present study was to investigate microplastic-associated bacterial communities collected in the coastal ecosystem of the bay of Brest (Brittany, France). The bay of Brest was recently studied for microplastic contamination; the mean concentration was estimated around 0.24 floating microplastic. $\mathrm{m}^{-3}$ dominated by polyethylene (PE), polypropylene (PP) and polystyrene (PS) fragments (Frère et al., 2017). In this study, floating microplastics collected during two sampling surveys and at two stations in the bay were characterized by manual sorting followed by Raman spectroscopy and associated bacterial communities were analyzed using high-throughput 16S rRNA gene amplicon sequencing to investigate: (a) taxa associated to microplastics and to the surrounding seawater encompassing both free-living and particle attached communities, and (b) the influence of the polymeric nature and size ranges of microplastics $(5-2 \mathrm{~mm}, 2-1 \mathrm{~mm}$ and $1-0.3 \mathrm{~mm}$ ) on the composition and structure of the bacterial communities. Because the genus Vibrio was commonly detected on microplastics, specific PCR were also performed to determine the presence / absence of potentially pathogenic Vibrio strains (namely V. aestuarianus and the V. splendidus polyphyletic group).

\section{Material and methods}

\section{Samples collection}

Sample collection was conducted in the bay of Brest (Brittany, France) during two sampling surveys conducted on October $21^{\text {th }}, 2015$ and December $9^{\text {th }}, 2015$. Two sites were sampled: site A1 was located close to a recreational marina in an area subjected to intense anthropogenic activities $\left(48^{\circ} 22^{\prime} 41.06 " \mathrm{~N}, 4^{\circ} 29^{\prime} 22.60^{\prime \prime} \mathrm{W}\right)$, and site $\mathrm{M} 1$ was located in the center of the bay $\left(48^{\circ} 20^{\prime} 34.59^{\prime \prime} \mathrm{N}, 4^{\circ} 30^{\prime} 6.29^{\prime \prime} \mathrm{W}\right)$ in an area characterized by the occurrence of a transitional vortex created by surface current at flood tide, concentrating floating debris coming from the north and the south of the bay (Frère et al., 2017). Samples were collected at 
surface water using a Manta trawl (335 $\mu \mathrm{m}$ mesh, rectangular net opening of 0.6 x $0.16 \mathrm{~m}$ ) and stored in sterilized glass jar on board. Three liters of surface seawater were also collected at each sampling station and filtered through $0.22 \mu \mathrm{m}$ Sterivex filters in sterile conditions. Filters were stored at $-20{ }^{\circ} \mathrm{C}$ and used for subsequent DNA extraction in order to assess both free-living (FL) and particle-attached (PA) communities present in seawater. Surface water quality parameters were monitored within the scope of the SOMLIT (Service d'Observation en Milieu LITtoral), the French Coastal Monitoring Network (http://somlit.epoc.ubordeaux1.fr/fr/) and are presented in supplementary table 1. The suspended particulate matter (SPM) in the Bay of Brest is mainly composed by phytoplankton (82\%), river POM (10\%) and macro-algae (8\%) (Liénart et al., 2017).

\section{Samples processing}

All collected microparticles were processed within 24 hours upon sample collection in rigorous sterile conditions throughout their manipulation with minimal freezing steps in order to avoid DNA alteration, loss or contamination. Morphological and chemical (Raman) features were recorded prior to DNA extraction in order to allow the clustering of microplastics as a function of their polymer nature within each size class.

Manual microparticles extraction was performed immediately upon return to the lab using forceps and a dissecting microscope under sterile conditions. All material (petri dish, filter, forceps) was sterilized, and forceps were systematically rinsed in $10 \%$ chlorine solution and milliQ water between manipulations of each particle. Visually identified microplastic-like particles were individually rinsed with sterile seawater before being dried and shortly stored in sterile WillCo-dish glass dishes at $-20{ }^{\circ} \mathrm{C}$ prior to spectroscopy analysis. Microplastic molecular composition was identified by Raman micro-spectroscopy using the method developed by (Frère et al., 2016), adapted here due to the need to maintain sterile conditions: extracted particles were kept in closed sterile WillCo-dish glass dishes exhibiting a top thin glass slide $(0.17 \mathrm{~mm}$ width) and spectroscopy analyses were realized through this glass slide. Preliminary manipulations have ensured that the Raman signal was not affected by the glass slide (data not shown).

Microplastics were exclusively made of fragments and they were isolated based on their collection date (October and December 2015), their sampling site (A1 and M1) and their polymer family (polyethylene (PE), polypropylene (PP) and polystyrene (PS)) before being pooled according to size range: 5-2 $\mathrm{mm} / 2-1 \mathrm{~mm} / 1-0.3 \mathrm{~mm}$. The pooling rate was adapted 
for each size class to ensure sufficient DNA quantity for subsequent $16 \mathrm{~S}$ amplicon sequencing (especially for the lowest size class $0.3-1 \mathrm{~mm}$ ). Accordingly, microplastic pools contained $\mathrm{n}=20$ particles in the $1-0.3 \mathrm{~mm}$ range, 8 for the $2-1 \mathrm{~mm}$ range and 4 for the $5-2 \mathrm{~mm}$ range. A total of one to five pools per polymer and size class were processed according to the available number of particles collected and identified by Raman micro-spectrometry in each category (Table 1). Pools were stored in $2 \mathrm{ml}$ tube at $-20^{\circ} \mathrm{C}$ prior to DNA extraction. Overall, the bacterial communities were investigated on a total of 47 pools of microplastics (MP) and 12 samples of seawater $(0.22 \mu \mathrm{m}$ Sterivex filters containing FL+PA bacteria).

\section{DNA extraction}

DNA extraction was performed (i) on the Raman identified microplastics and (ii) directly on the $0.22 \mu \mathrm{m}$ filters used for seawater filtration (see section 1. Samples collection). Therefore the communities revealed in the seawater fraction encompassed both free-living (FL) and particle associated (PA) bacteria. DNA extraction was done using phenol chloroform: after adding $800 \mu \mathrm{l}$ of TNE buffer, $50 \mu \mathrm{l}$ of SDS $10 \%, 50 \mu 1$ of lauryl sarkosyl $10 \%$ and $50 \mu 1$ of proteinase K (20 mg.g-1) were added to each tube. Tubes were incubated at $55{ }^{\circ} \mathrm{C}$ for 2 hours before being homogenized and transferred in tubes containing silica beads (Lysing Matrix B, $2 \mathrm{~mL}$ MP Biomedicals tube). Samples were then centrifuged at $11000 \mathrm{~g}$ for $3 \mathrm{~min}$ for mechanical lysis. Aqueous phases were transferred to clean $2 \mathrm{ml}$ tubes, $700 \mu \mathrm{l}$ of phenol:chloroform: isoamyl alcohol (25:24:1) were added and tubes were centrifuged at 8000 $\mathrm{g}$ for $10 \mathrm{~min}$ at room temperature. $700 \mu \mathrm{l}$ of chloroform was added and tubes were centrifuged at $8000 \mathrm{~g}$ for $10 \mathrm{~min}$ at room temperature. Aqueous phases were transferred in clean $2 \mathrm{ml}$ tubes and DNA precipitation was realized with $1500 \mu \mathrm{l}$ of absolute ethanol by inversion (this step was repeated 10 times) after which tubes were centrifuged at $14000 \mathrm{~g}$ for $15 \mathrm{~min}$ at $4{ }^{\circ} \mathrm{C}$. Aqueous phases were eliminated, $500 \mu \mathrm{l}$ of ethanol $70 \%$ were added and tubes were centrifuged at $14000 \mathrm{~g}$ for $10 \mathrm{~min}$ at $4{ }^{\circ} \mathrm{C}$. Aqueous phases were eliminated and pellets in tube's bottom were dried with a SpeedVac for $5 \mathrm{~min}$ at $30^{\circ} \mathrm{C} .30 \mu \mathrm{l}$ of ultrapure water were added and tubes with DNA were stored at $4^{\circ} \mathrm{C}$ before amplicon sequencing analysis. Samples were further stored at $-20^{\circ} \mathrm{C}$ prior to $\mathrm{PCR}$ analysis.

\section{16S amplicons sequencing}

Bacterial community assemblages were determined using amplicons sequencing of the $16 \mathrm{~S}$ rRNA gene V4-V5 region according to (Huse et al., 2014). We amplified the V4 - V5 hypervariable region of the bacterial $16 \mathrm{~S}$ rRNA gene using a combination of the barcoded 
forward primer 518F (5'-CCAGCAGCYGCGGTAAN-3') and a mix of three indexed reverse primer 926R (5'-TGARTTTNCTTAACTGCC-3'; 5'-TGAGTTTCTTTAACTGCC-3'; 5'TNAGTTTCCTTA TCTGCC-3' in 8:1:1 ratio respectively). The following PCR conditions were used: initial denaturation of thirty cycles at $94^{\circ} \mathrm{C}$ for $3 \mathrm{~min}, 94{ }^{\circ} \mathrm{C}$ for $30 \mathrm{sec}, 58{ }^{\circ} \mathrm{C}$ for $45 \mathrm{sec}, 72{ }^{\circ} \mathrm{C}$ for $1 \mathrm{~min}$ following by $72{ }^{\circ} \mathrm{C}$ for $2 \mathrm{~min}$ and $4{ }^{\circ} \mathrm{C}$ at infinite. PCR products were purified with the Agencourt AMPure XP kit. Due to the presence of ca. 750 bp long unspecific PCR products, we quantified PCR product of the expected size (ca. $410 \mathrm{bp}$ ) on bioanalyzer high-sensitivity chips (Agilent), to then pool libraries in equimolecular quantities based on these DNA concentrations. We finally removed unwanted PCR products by size selecting the library pool on a BluePippin 300-500 bp selection cassette (Sage biosciences). Amplicon libraries were sequenced in a 2x250 bp paired-end format using the Illumina MiSeq platform at the Josephine Bay Paul Center Keck facility (Marine Biological Laboratory, Woods Hole MA, U.S.A). Raw data were deposited on the Ifremer Sextant website (http://dx.doi.org/10.12770/c210bf1e-a55c-440f-810f-8f68b1ef9a9d) and reads with metadata are publicly available on the VAMPS portal (www. vamps.mbl.edu) under the project name LQM_MPLA_Bv4v5.

\section{Processing sequences}

Data were demultiplexed and barcodes were trimmed off the reads by the sequencing provider. Sequences were filtered, clustered and assigned with the FROGS pipeline (Find Rapidly OTU with Galaxy Solution) using the Galaxy platform (Escudié et al., 2017). Briefly, paired-end reads were merged using Flash (1.2.11) with an overlap length of $90 \mathrm{pb}$ and a minimum length of $340 \mathrm{pb}$. Next, sequences were filtered using Cutadapt (1.7.1) to remove primers and using UCHIME (v7) of USEARCH package (1.1.3) to remove chimeras (Edgar, 2010). Dereplication was used to group strictly identical sequences using a homemade script. SWARM (1.2.2) was used for clustering reads into operational taxonomic units (OTU) with a first run including an aggregation distance equal to 1 (i.e. high OTU definition linear complexity) and a second run with an aggregation distance equal to 3 on the seeds of the first SWARM quadratic complexity (Mahé et al., 2014). Representative sequences were aligned using NCBI Blast+ (2.2.29) with the database SILVA 123 (Camacho et al., 2009). Singletons (that is, sequences found once in one sample only) were excluded after quality filtering and global trimming for downstream analyses.

\section{Polymerase chain reaction (PCR) analysis}


The detection of Vibrio splendidus and V. aestuarianus by real-time PCR was adapted from previously published protocols (Saulnier et al., 2009, 2017) allowing the specific detection of all bacteria from $V$. splendidus polyphyletic group (V. lentus, V. cyclitrophicus, V. pomeroyi, $V$. tasmaniensis, V. splendidus, V. kanaloae, V. gigantis and V. crassostreae), and the specific detection of $V$. aestuarianus strain. Threshold cycles $(\mathrm{Ct})$, defined as the cycle at which a statistically significant increase in fluorescence output above background is detected, were calculated automatically by the thermocycler software. A valid run was defined as a run exhibiting no amplification of the negative control and amplification of the positive control fulfilling the following requirements: difference between duplicated values must not exceed $0.5 \mathrm{Ct}$, and $\mathrm{Ct}$ value must be below 37. A sample was defined as positive when it exhibited an exponential accumulation of fluorescence and a valid cycle threshold.

\section{Data analysis and statistics}

Venn diagrams were generated using the $\mathrm{R}$ packages Vegan and Venn, respectively (R Core team, 2015). For subsequent analyses of alpha- and beta-diversity, read counts were divided by the total number of reads in each sample to compensate for differential sequencing depth per sample. Alpha diversity based on observed number of OTU, species richness, Shannon and Simpson diversity indices were calculated for each sample type (microplastic and seawater). Whenever one-way analysis of variance (ANOVA) assumptions were met (normality, heterogeneity of variances, outliers), the latter was used to assess the effect of sample types on microbial diversity (Chambers et al., 1992), and Tukey HSD (honest significant difference) test was used for pairwise comparisons. Beta-diversity analyses were done using the R packages ggplot2 and phyloseq (McMurdie and Holmes, 2013). Bacterial assemblages of microplastics (PE, PP and PS) and of seawater samples were represented by mean relative percentage ( \pm standard deviation) and compared using the Jaccard and BrayCurtis diversity indices. Results of distance matrix were visualized using nonmetric multidimensional scaling (nMDS). Statistical comparison of bacterial communities between sample types, stations and surveys was done by permutational multivariate analysis of variance (PERMANOVA) and the homogeneity of group dispersions (variances) was subsequently tested (PERMDISP). Both analyses were performed using the R package Vegan (Anderson, 2001). Finally, the potential presence of taxonomic groups (i.e., biomarkers) that may explain the difference between bacterial communities in different sample was explored with LEfSe (Segata et al., 2011) in the Galaxy framework. The linear discriminant analysis (LDA) effect size allows identifying statistically significant groups characterized by their 
degree of consistency in relative abundance together with their effect relevance, in each sample class (Segata et al., 2011). A p-value of 0.05 was set as the significance level for all analyses.

\section{Results and discussion}

\section{Microplastics and seawater shared a high proportion of taxa}

After quality filtering and chimera checking of the initial 21,660,493 reads, 8,055,314 reads were retained (mean reads per sample $=136,530$ ), ranging from 34,984 to 324,667 reads in samples MP004 (PE, 5 - 2 mm, station A1, December) and MP023 (PP, 1 - 0.3 mm, A1, December), respectively. In total, high-quality sequences were clustered into 1,548 operational taxonomic units (OTU) with 1,395 for seawater samples and 1,540 for microplastic samples. Microplastic and seawater samples presented rarefaction curves with a stationary phase indicating sufficient depth of sequencing to account for most of the taxa amplified in both microplastic and seawater matrices (data not shown). The seawater samples (encompassing both free-living (FL) and natural particle-attached (PA) bacteria) were predominantly (around $84 \%$ ) composed of rare OTU (hereafter defined with a mean relative abundance per sample $<0.01 \%$ ) whereas abundant OTU (mean relative abundance per sample $>1 \%$ ) were rare in all sample types (around $4 \%$ ). Microplastics and seawater shared a high number of OTU: $78 \pm 4 \%$ of the OTU recorded on microplastics were shared with seawater; and $98 \pm 0.04 \%$ of the OTU identified in seawater were shared with microplastics (Figure 2).

The high proportions of shared OTU between MP and seawater (FL+PA communities) suggest that the local surrounding seawater has likely provided most of the bacterial communities identified on collected microplastics. The local environment was already suggested to serve as a bacterial source for plastic biofilm organisms for plastic sheets deployed in a coastal harbor (De Tender et al., 2017). The fraction of shared OTU between microplastics and surrounding seawater was however much lower (3.5 to $8.6 \%$ ) in a study conducted in the North Atlantic Ocean (Zettler et al., 2013). The low proportion of suspended matter in oligotrophic oceanic waters (as compared to eutrophic coastal waters studied here; Supplementary table 1) could partly explain this difference as the fraction analyzed on $0.2 \mu \mathrm{m}$ sterivex filters may be different between the two studies, i.e. mostly composed by FL communities in Zettler et al. (2013) vs. FL and PA communities in our study. 
Microplastics presented a larger number of unique OTU $(n=335 \pm 60$ OTU; 10 to $25 \%$ of the total identified OTU) than seawater, exhibiting few unique OTU ( $\mathrm{n}=27 \pm 1$ OTU; $2 \%$ of the total identified OTU) (Figure 2). A unique OTU is defined as an OTU exclusively found in a single matrix (i.e. microplastic or seawater), as opposed to a shared OTU that is detected in both microplastics and seawater samples. Interestingly, among the unique microplastic OTU, $94 \pm 4 \%$ were shared between PE, PP and PS, and 0.2 to $1.6 \%$ were specific to each of the three polymer families (Figure 2). Fraction of shared OTU between polymers was higher than the 30 to $40 \%$ found between PE (n=3) and PP (n=3) in the study of Zettler et al. (2013), which could be due to the microplastics life history upon their entrance in marine waters: microplastics collected closed to the source as in the bay of Brest and therefore more recently colonized, may exhibit more uniform assemblages. Overall, the high proportion of shared OTU among polymers observed here suggests a "core" of bacteria characterizing the plastic substrate, regardless of the polymer type, as reported in (Zettler et al., 2013).

\section{High bacterial diversity is observed on microplastics}

For both surveys, microplastic bacterial communities richness (number of observed OTU) appeared significantly higher than the one of seawater bacterial (FL+PA) community (p-value $=<0.001$ and 0.006, respectively; Supplementary table 2), consistent with previous studies (Bryant et al., 2016; De Tender et al., 2015, 2017; Debroas et al., 2017; Dussud et al., 2018). This likely reflects the colonization process and biofilm formation, often characterized by complex microbial competition and increased species richness (Datta et al., 2016; Jackson et al., 2001). In October, microplastic bacterial communities showed a significantly higher number of observed OTUs and Shannon index than seawater communities (Supplementary table 2), presumably due to the high proportion of rare OTU on the plastic matrix. On the opposite, no significant difference in evenness (reflected by the Shannon and Simpson indexes) was observed between microplastics and seawater in December. Among the three polymer families (PE, PP and PS), no significant difference in alpha-diversity was observed in October in terms of species richness and evenness, while PS collected in December showed a significantly greater Shannon diversity index than PE ( $\mathrm{p}$-value $=0.029)($ Supplementary table 2).

To our knowledge very few studies have investigated the alpha-diversity of plastic debris bacterial communities as a function of the polymer type and no data is available for the small microplastic size range we studied herein. The present study is the first to attempt the discrimination of potential differences in bacterial assemblages using metabarcoding in such 
low size classes $(0.3-1 \mathrm{~mm} ; 1-2 \mathrm{~mm} ; 2-5 \mathrm{~mm})$ for three distinct polymers (PE, PP, PS) collected in a coastal ecosystem. The difficulty of these analyses relies on the need to efficiently characterize the morphological and polymer nature of plastic particles down to a very small size in a very short term and in sterile conditions to avoid bacterial community shift. This is especially true for the lowest size class $(0.3-1 \mathrm{~mm})$ for which DNA extraction on individual particle did not provide enough material for subsequent $16 \mathrm{~S}$ amplicon sequencing analyses (data not shown), thus implying a pooling procedure per polymer type prior to DNA extraction. In addition the DNA extraction is destructive for microplastics due to the solvents used, thus requiring that the polymer characterization must be performed beforehand. Due to these constraints most studies discriminated the influence of polymer type using bigger particles (mainly pellets), small subsamples, or run their analysis in the whole microplastic pool without necessarily discriminating the polymer nature (Supplementary table 3 ). The strength of the present study lays in the comparison of different size classes and different polymers in a relatively large sample set ( $\mathrm{n}=464$ microplastics) sampled in one coastal ecosystem rich and diverse in terms of habitats, flora and fauna, and at the center of many human activities. The quantity of particles analyzed as well as the time required to process samples remained also often unknown, while these parameters are crucial for the evaluation of the protocol quality and representativeness of the sample size (Supplementary table 3).

No difference in bacterial species richness or evenness was observed as a function of particle size within the microplastic size range $(300 \mu \mathrm{m}-5 \mathrm{~mm}$, data not shown). For bigger plastic debris, surface area was shown to determine the abundance of fouling organisms (Fazey and Ryan, 2016). For instance, higher bacterial and eukaryotic richness were observed on mesoplatic sized PE (5mm-20cm) compared to $300 \mu \mathrm{m}-5 \mathrm{~mm}$ microplastics primarily made of PE (Debroas et al., 2017), presumably due to differences in crystallinity and molecular weight between meso- and microplastics PE.

\section{Bacterial communities colonizing microplastics}

\subsection{Characterization of bacterial assemblages colonizing microplastics}

For both sampling surveys, the bacterial communities structure were different between microplastics and the surrounding seawater as showed by separate clustering in the nMDS plot (Figure 3). This result was confirmed by statistical analyses using Bray-Curtis (PERMANOVA, p-value $=0.001$ for October and December) (Supplementary table 4$)$ as well as Jaccard similarity index (PERMANOVA, p-value $=0.001$ for October and December) 
(data not shown). Microplastics seemed to harbor different bacterial communities as compared to seawater (FL+PA) in terms presence/absence but also in terms of relative abundance of bacterial communities. Heterogeneity of variances was also observed (Supplementary table 5); however when the group with the largest dispersion also has the largest sample number (as it is the case here due to unbalanced sampling design) the PERMANOVA test becomes quite conservative and the observed significance differences can be confidently considered robust (Anderson \& Walsh, 2013). The outputs of the PERMDISP analysis also showed differences between microplastics and seawater bacterial communities both in terms of centroid location and data dispersion (Supplementary figure 1A). Differences between water and plastic associated bacterial communities were demonstrated in urban freshwater ecosystems (Hoellein et al., 2014; McCormick et al., 2014, 2016), in North Atlantic and North Pacific oceans (Amaral-Zettler et al., 2015; Debroas et al., 2017; Zettler et al., 2013), in the North Sea (De Tender et al., 2015), in the Western Mediterranean Basin (Dussud et al., 2018) as well as for plastics incubated in coastal waters and sediments (De Tender et al., 2017; Harrison et al., 2014; Oberbeckmann et al., 2014). However, such distinction cannot be rigorously ascertained in the present study) because (i) a clear distinction between FL and PA bacterial assemblages present in the collected seawater was not performed here and (ii) a dilution effect may have masked the relative importance of PA communities. Indeed, collected seawater was filtered on $0.22 \mu \mathrm{m}$ filters which concentrated both free-living ( $3-0.22 \mu \mathrm{m}$ ) and particle-associated bacterial communities (> $3 \mu \mathrm{m})$, making the discrimination of both fractions not possible. In addition, even though the SOMLIT data confirmed the presence of suspended organic and particulate matter (Particulate Organic Carbon $($ POC $)=125-134 \mu \mathrm{g} \mathrm{L}^{-1}$; Suspended Particulate Matter $\left.(\mathrm{SPM})=1.3-2.5 \mathrm{mg} \mathrm{L}^{-1}\right)$ in the seawater at the time of sampling (Supplementary table 1) we cannot exclude a potential dilution effect considering the difference between the quantity of natural particle analyzed per filter (estimated to $1.3-2.5 \mathrm{mg}$ ) and the quantity of microplastic used for DNA extraction (maximum mass estimated at 9.8 - 61.5 mg per pool). Thus, an appropriate "particle" control, well characterized in terms of particle matter quantity and quality, and distinct from a "freeliving" control is lacking in the present study to confirm the specificity of microplastic bacterial communities. For instance, Oberbeckmann et al. (2016) demonstrated that even though PET bottles-attached bacterial communities were distinct from free-living seawater communities, they were similar to other types of particle-associated or glass-attached communities collected in the surrounding seawater (with the exception of some unique OTU identified on PET). However, investigations conducted in a larger sample set of various PMD 
$(n=72)$ at a large spatial scale (Western Mediterranean Basin) provided contrasted results with a significant distinction between FL, PA and PMD-attached bacterial communities. Despite the presence of a large proportion of OTUs being able to colonize indifferently PMD or PA, and to subsequently free themselves (Dussud et al., 2018) FL bacteria were dominated by Alphaproteobacteria (mainly Pelagibacter sp.). PA bacteria, on the other hand, were dominated by Alphaproteobacteria (mainly Erythrobacter sp.) and Gammaproteobacteria (mainly Alteromonas sp.) while PMD was predominantly colonised by Cyanobacteria and Alphaproteobacteria. Plastic debris exhibiting different bacterial communities than other marine substrate was also demonstrated in previous studies conducted in freshwater (McCormick et al., 2014). This was however not necessarily consistently observed when comparing different type of hard substrates including plastic (Hoellein et al., 2014).

At the phylum level, bacterial communities of all sample types (microplastics and seawater) were dominated by Proteobacteria $(60.72 \pm 5.41 \%)$, Bacteroidetes $(20.58 \pm 4.64 \%)$ and Cyanobacteria $(9.09 \pm 7.40 \%)$ representing major bacterial classes colonizing substrate in marine ecosystems (Keswani et al. 2016). Microplastics were mainly colonized by Alpha- and Gammaproteobacteria (17.67 $\pm 5.28 \%$ and $40.76 \pm 8.43 \%$, respectively), which were shown to act as primary colonizers, and Flavobacteria (Bacteroidetes, $16.83 \pm 2.64 \%$ ), which appeared to act as secondary colonizers (Lee et al., 2008; Oberbeckmann et al., 2015).

At the family level, Flavobacteriaceae and Rhodobacteraceae were identified in relatively high abundance in all sample types (microplastics and seawater) with $16.06 \pm 1.23 \%$ and $13.40 \pm 4.03 \%$, respectively. The families of Vibrionaceae $(9.88 \pm 8.27 \%)$ and Pseudoalteromonadaceae $(8.24 \pm 6.95 \%)$ were commonly found in microplastic samples but rarely observed in seawater community encompassing both FL and PA bacteria (Figure 4). However, the low relative abundance of these families in seawater could simply be due to a dilution effect, despite the fact that these bacteria may densely populate natural particles. . Both Vibrionaceae and Pseudoalteromonadaceae families were similarly found on marine plastic litter collected along the Belgian coast while rarely observed in surrounding seawater and sediments (De Tender et al., 2015). Very few information focusing on the Pseudoalteromonadaceae family is available in the microplastic literature, while several studies reported that the genus Pseudoalteromonas was previously detected on plastics (Zettler et al., 2013) or as a dominant genus on PET bottles (Oberbeckmann et al., 2014, 2016). This genus is known as a hydrocarbon degrader (Lin et al., 2009) and has often been observed associated with marine algae. 
At the genus level, Litoreibacter and Vibrio were commonly detected on microplastics, while Candidatus Actinomarina, Synechococcus, Owenweeksia, NS3 marine group and NS5 marine group appeared as biomarkers of seawater. Interestingly, the genus Vibrio has been very frequently detected in association with plastic debris for the past few years (Dussud et al., 2018; Kirstein et al., 2016; Oberbeckmann et al., 2016; Schmidt et al., 2014) and even represented up to $24 \%$ on PP pellet collected in the North Atlantic (Zettler et al., 2013). However, this observation is not consistent as Bryant et al. (2016) and Oberbeckmann et al. (2017) did not observe any enrichment of Vibrio on microplastics. Vibrios are ubiquitous marine bacteria belonging to diverse ecological populations that are ecologically and metabolically different and pursue different lifestyles in the water column (free living, particle and animal-associated) (Le Roux et al., 2016). The vibrio genus comprises numerous pathogenic species for human, fish and shellfish, and some of which (V. coralliilyticus, $V$. harveyi, V. splendidus, V. parahaemolyticus, V. alginolyticus and V. fluvialis) that have been detected on microplastics (Dussud et al., 2018; Kirstein et al., 2016; Schmidt et al., 2014), thus there is some concerns that the ever increasing microplastic contamination in marine environment may influence their population dynamics, and ultimately pathogen emergence. For instance, rapid growth of vibrios has been observed in association with diatom bloom or algae proliferation (Gilbert et al., 2012; Nealson and Hastings, 2006) suggesting the importance of substrate and habitat occurrence on particle-associated vibrios dynamic in the marine environment. In our study, the genus Vibrio was recovered in high abundance in microplastic samples (1.5 to $18.6 \%$ ) but the specificity of Vibrio genus to colonize plastic as compared to other natural particulate matter has yet to be clarified. . To further investigate the presence of potential pathogenic Vibrio strains on microplastics, we assayed two Vibrio species $V$. splendidus-related and $V$. aestuarianus that have frequently been associated with massive mortality events in Pacific oyster in France alongside with the herpesvirus OsHV-1 (Le Roux et al., 2002; Saulnier et al., 2009). Some strains of these bacteria are known to exhibit virulent abilities in experimental infection trials (De Decker and Saulnier, 2011) and it was recently demonstrated that these agents can act solely or in concert (polymicrobial disease) in the field (Lemire et al., 2015; Petton et al., 2015). V. splendidus related species were commonly detected on $77 \%$ of the MP samples (36 out of 47 pools exhibited Ct values comprised between 19.4 and 34.9) while V. aestuarianus strain was never detected at the threshold defined above (supplementary Table 6). None of these species were ever detected in seawater samples by qPCR. This result raises concern about the transport of potential 
pathogens by microplastics, as recently demonstrated for Aeromonas salmonicida (Virsek et al., 2017).

\subsection{Bacterial assemblages were influenced by polymer nature but not by particle size}

Size and therefore surface area did not appear as a main factor in shaping microplastic bacterial communities at the microscale (0.3-1 vs. 1-2 vs. 2-5mm) as no significant difference in terms of OTU composition and structure was detected among microplastic size ranges ( $\mathrm{p}>$ 0.05 for both PERMANOVA and PERMDISP; Supplementary Tables 4 and 5; Supplementary Figure 1B). This is not necessarily true when comparing bigger plastic debris as difference in community structures was recently demonstrated between mesoplatic sized PE $(5 \mathrm{~mm}-20 \mathrm{~cm})$ as compared to the microplastics $(300 \mu \mathrm{m}-5 \mathrm{~mm})$ primarily made of PE (polymer nature identified on a separated subsample; Debroas et al. 2017).

On another hand, the microplastic bacterial community composition was significantly influenced by the polymer family with PS presenting a distinct bacterial community to those of PE and PP in December 2015 (PERMANOVA, p-value $=0.013$ and p-value $=0.017$, respectively) (Supplementary table 4). It is noteworthy that a great heterogeneity in dispersion was observed for the PE communities while PS and PP displayed more tightly clustered groups (PERMDISP, p-value $=0.004$; Supplementary table 5 and Supplementary figure 1C). As most PS collected in the bay of Brest was found in the form of foam fragments, the distinct bacterial communities may be related to difference in terms of physical structure and/or chemical load. Similarly, PS was also found to be distinct from PE and PP in terms of community assemblage and structure in earlier studies conducted in the Atlantic and Pacific oceans (Amaral-Zettler et al. 2015). Difference in structural and/or chemical (plasticizers, dyes) properties observed among polymer families is likely to influence bacterial communities and dynamics (De Tender et al., 2015) even though studies specifically addressing this point are still lacking (Oberbeckmann et al., 2015). For instance, PE ropes and sheets deployed at the same coastal location quickly exhibited distinct bacterial structures while being made by the same polymer and incubated in the same habitat (De Tender et al., 2017) suggesting that particle shape (and/or unknown additive compounds) is a determining factor influencing bacterial colonisation of PMD for a given polymer.

\subsection{Spatial and temporal influence in bacterial communities composition}

- Temporal variability 
Bacterial assemblages were different across surveys (October and December 2015) for all sample types (microplastics and seawater) (Figure 3, PERMANOVA, p-value $=0.004$ for seawater, p-value $=0.001$ for microplastics; Supplementary table 4). While homogeneity of dispersion was observed in seawater communities collected in October and December, a significant heterogeneity of dispersion was demonstrated in the microplastics communities from these two surveys (PERMDISP, p-value $=0.302$ and 0.001 , for seawater and microplastics, respectively; Supplementary table 5 and Supplementary figure 1D-E). As a consequence, change in the microplastic community structure between both sampling times is likely due to both location and dispersion effects). Temporal variability in bacterial assemblages associated to microplastics was also found in previous studies conducted in freshwater (Hoellein et al., 2014) and coastal ecosystems (De Tender et al., 2017; Hoellein et al., 2014; Lee et al., 2008; Oberbeckmann et al., 2014). As a consequence, different taxonomic group significantly discriminated the microplastic matrix and the seawater bacterial communities according to sampling date. The Sphingomonadales order and Psychoserpens genus were biomarkers of microplastics in October samples whereas Bacilli (Firmicutes) and Tenacibaculum, Leucothrix, Oleibacter and Psychomonas genera were biomarkers in December samples (Figure 5). The phylum Firmicutes is typically related to seawage associated bacteria (e.g. Enterococcus, Lactococcus, Leuconostoc, Staphylococcus and Streptococcus genera) (Oberbeckmann et al., 2015) and was previously detected on MP collected in the North Adriatic Sea (Viršek et al., 2017).

In terms of polymer differences, the Pseudomonadales order was detected as a PE biomarker in October 2015. In December 2015, the Oceanospirillales order (Gammaproteobacteria), which was shown to play a role in oil spill degradation (Mason et al., 2012), and the Propionispira genus, described by Ueki et al. (2014), were found as biomarkers of PE. The Alphaproteobacteria class and the Holophagae order (Acidobacteria) were biomarker of PP. Alphaproteobacteria constitute early colonizers commonly found on plastic debris, while Acidobacteria was previously found significantly associated with PET (and in a lesser extent PS) mesoplastics (Debroas et al., 2017) and in plastic marine derbis in North Sea samples (De Tender et al., 2015). Finally, Rhodospirillaceae family (previously detected on PP and PE; Zettler et al., 2013), Roseovarius (belonging to the Roseobacter group common in coastal and open oceans) and Nitrosomonas genera (known to oxide ammonia) were biomarkers of PS in this study. 
PERMANOVA analyses showed a significant difference in bacterial communities composition between A1 and M1 in December. The M1 station was dominated by the Moraxellaceae family (42.3\%) and the Psychrobacter genus (41.7\%) while station A1 was dominated by the 34P16 order (Gammaproteobacteria, unknown family and genus) (16.4\%). No reliable spatial analysis can be performed here due to the low MP sample size in M1 ( $n=4$ pools containing a total of $40 \mathrm{MP})$ as compared to A1 ( $n=43$ pools containing 424 MP) (Table 1), but spatial variability in plastic-associated communities were more rigorously assessed in previous studies conducted in the North Sea (Oberbeckmann et al., 2015; De Tender et al., 2017) and in the North Pacific and North Atlantic Oceans (Amaral-Zettler et al., 2015).

While temporal differences were only supported by two sampling times herein and must therefore be considered with cautious, these results open up a relevant issue for understanding the temporal and spatial variability of microplastics's microbial communities at the scale of a bay taking into account the sources and consequences for human activities, both being major points for decision support.

\section{Conclusion}

The efficient colonisation of microplastics floating at sea emphasizes the fact that this new man-made habitat may facilitate the persistence and long range dispersal of microorganisms. As a consequence plastic bacterial communities are likely to be dynamic and able to quickly adapt to their changing environment. For instance, hydrodynamics modeling work demonstrated that $60 \%$ of the floating microplastics present in the bay of Brest are expelled from the bay after 10 days (Frère et al., 2017), and the fate of the associated bacterial communities remains unknown in the Iroise Sea and the Atlantic Ocean.

The Vibrio genus was commonly found on the collected microplastics and V. splendidus related species harboring potential oyster pathogens were detected on most microplastic pools (77\%). This raises questions about the role of microplastics on pathogenic Vibrio species transport and potential disease emergence and much work has to be done on clarifying the specificity of these bacteria for the plastic substrate. To investigate the ecological effects of microplastic pollution on pathogens emergence and virulence, proper 'natural particulate matter' controls must be considered in field surveys to avoid any misinterpretations. In addition, risk evaluation based on bacterial identification should be completed by more indepth studies involving RNA sequencing of pathogenicity markers coding for instance for 
toxins, adhesins, or invasins (Goudenège et al. 2015) and experimental testing of virulence in laboratory trials (Labreuche et al., 2006).

542

543

544

\section{Acknowledgments}

This work was supported by the ANR CESA (ANR-15-CE34-0006-02, NANOPLASTICS project) and by the Unique Inter-ministerial Fund (FUI) and the local communities (CR Bretagne, CR PACA, CD29, CATPM and Brest Métropole) as part of the MICROPLASTIC2 project (Région Bretagne 0214/15008381/00001897, Bpifrance D0S0028206/00). L. Frère was funded by a French doctoral research grant (DDP150097 ARED-FRERE) from Brest Métropole (50\%) and University of Brest (50\%).

\section{References}

Anderson, M. J. and Walsh, D. C. I. (2013), PERMANOVA, ANOSIM, and the Mantel test in the face of heterogeneous dispersions: What null hypothesis are you testing? Ecological Monographs, 83: 557-574.

Amaral-Zettler, L.A., Zettler, E.R., Slikas, B., Boyd, G.D., Melvin, D.W., Morrall, C.E., Proskurowski, G., Mincer, T.J., 2015. The biogeography of the Plastisphere: implications for policy. Front. Ecol. Environ. 13, 541-546.

Bryant, J.A., Clemente, T.M., Viviani, D.A., Fong, A.A., Thomas, K.A., Kemp, P., Karl, D.M., White, A.E., DeLong, E.F., 2016. Diversity and activity of communities inhabiting plastic debris in the North Pacific Gyre. MSystems 1, e00024-16.

Camacho, C., Coulouris, G., Avagyan, V., Ma, N., Papadopoulos, J., Bealer, K., Madden, T.L., 2009. BLAST+: architecture and applications. BMC Bioinformatics 10, 421.

Carlton, J.T., Chapman, J.W., Geller, J.B., Miller, J.A., Carlton, D.A., McCuller, M.I., Treneman, N.C., Steves, B.P., Ruiz, G.M., 2017. Tsunami-driven rafting: Transoceanic species dispersal and implications for marine biogeography. Science 357, 1402-1406.

Chambers, J.M., Freeny, A., Heiberger, R.M., 1992. Analysis of variance; designed experiments. Stat. Models S 145-193.

Datta, M.S., Sliwerska, E., Gore, J., Polz, M.F., Cordero, O.X., 2016. Microbial interactions lead to rapid micro-scale successions on model marine particles. Nat. Commun. 7.

De Decker, S., Saulnier, D., 2011. Vibriosis induced by experimental cohabitation in Crassostrea gigas: evidence of early infection and down-expression of immune-related genes. Fish Shellfish Immunol. 30, 691-699.

De Tender, C.A., Devriese, L.I., Haegeman, A., Maes, S., Ruttink, T., Dawyndt, P., 2015. Bacterial community profiling of plastic litter in the Belgian part of the North Sea. Environ. Sci. Technol. 49, 9629-9638. 
De Tender, C., Devriese, L.I., Haegeman, A., Maes, S., Vangeyte, J., Cattrijsse, A., Dawyndt, P., Ruttink, T., 2017. Temporal Dynamics of Bacterial and Fungal Colonization on Plastic Debris in the North Sea. Environ. Sci. Technol. 51, 7350-7360.

Debroas, D., Mone, A., Ter Halle, A., 2017. Plastics in the North Atlantic garbage patch: a boat-microbe for hitchhikers and plastic degraders. Sci. Total Environ. 599, 1222-1232.

Dussud, C., Meistertzheim, A.L., Conan, P., Pujo-Pay, M., George, M., Fabre, P., Coudane, J., Higgs, P., Elineau, A., Pedrotti, M.L., 2018. Evidence of niche partitioning among bacteria living on plastics, organic particles and surrounding seawaters. Environ. Pollut. 236, 807-816.

Escudié, F., Auer, L., Bernard, M., Mariadassou, M., Cauquil, L., Vidal, K., Maman, S., Hernandez-Raquet, G., Combes, S., Pascal, G., 2018. FROGS: Find, Rapidly, OTUs with Galaxy Solution. Bioinformatics. https://doi.org/10.1093/bioinformatics/btx791

Fazey, F.M., Ryan, P.G., 2016. Biofouling on buoyant marine plastics: An experimental study into the effect of size on surface longevity. Environ. Pollut. 210, 354-360.

Frère, L., Paul-Pont, I., Moreau, J., Soudant, P., Lambert, C., Huvet, A., Rinnert, E., 2016. A semi-automated Raman micro-spectroscopy method for morphological and chemical characterizations of microplastic litter. Mar. Pollut. Bull. 113, 461-468.

Frère, L., Paul-Pont, I., Rinnert, E., Petton, S., Jaffré, J., Bihannic, I., Soudant, P., Lambert, C., Huvet, A., 2017. Influence of environmental and anthropogenic factors on the composition, concentration and spatial distribution of microplastics: a case study of the Bay of Brest (Brittany, France). Environ. Pollut. 225, 211-222.

Gilbert, J.A., Steele, J.A., Caporaso, J.G., Steinbrück, L., Reeder, J., Temperton, B., Huse, S., McHardy, A.C., Knight, R., Joint, I., others, 2012. Defining seasonal marine microbial community dynamics. ISME J. 6, 298-308.

Goldstein, M.C., Carson, H.S., Eriksen, M., 2014. Relationship of diversity and habitat area in North Pacific plastic-associated rafting communities. Mar. Biol. 161, 1441-1453.

Goudenège, D., Travers, M.A., Lemire, A., Petton, B., Haffner, P., Labreuche, Y., Tourbiez, D., Mangenot, S., Calteau, A., Mazel, D., 2015. A single regulatory gene is sufficient to alter Vibrio aestuarianus pathogenicity in oysters. Environ. Microbiol. 17, 4189-4199.

Harrison, J.P., Sapp, M., Schratzberger, M., Osborn, A.M., 2011. Interactions between microorganisms and marine microplastics: a call for research. Mar. Technol. Soc. J. 45, $12-20$.

Harrison, J.P., Schratzberger, M., Sapp, M., Osborn, A.M., 2014. Rapid bacterial colonization of low-density polyethylene microplastics in coastal sediment microcosms. BMC Microbiol. 14, 232. https://doi.org/10.1186/s12866-014-0232-4

Hoellein, T., Rojas, M., Pink, A., Gasior, J., Kelly, J., 2014. Anthropogenic Litter in Urban Freshwater Ecosystems: Distribution and Microbial Interactions. PLoS ONE 9, e98485. https://doi.org/10.1371/journal.pone.0098485

Huse, S.M., Welch, D.B.M., Voorhis, A., Shipunova, A., Morrison, H.G., Eren, A.M., Sogin, M.L., 2014. VAMPS: a website for visualization and analysis of microbial population structures. BMC Bioinformatics 15, 41. 
Jackson, C.R., Churchill, P.F., Roden, E.E., 2001. Successional Changes in Bacterial Assemblage Structure During Epilithic Biofilm Development. Ecology 82, 555-566. https://doi.org/10.1890/0012-9658(2001)082[0555:SCIBAS]2.0.CO;2

Jokiel, P.L., 1990. Long-distance dispersal by rafting: reemergence of an old hypothesis. Endeavour 14, 66-73.

Keswani, A., Oliver, D.M., Gutierrez, T., Quilliam, R.S., 2016. Microbial hitchhikers on marine plastic debris: human exposure risks at bathing waters and beach environments. Mar. Environ. Res. 118, 10-19.

Kirstein, I.V., Kirmizi, S., Wichels, A., Garin-Fernandez, A., Erler, R., Löder, M., Gerdts, G., 2016. Dangerous hitchhikers? Evidence for potentially pathogenic Vibrio spp. on microplastic particles. Mar. Environ. Res. 120, 1-8.

Labreuche, Y., Lambert, C., Soudant, P., Boulo, V., Huvet, A., Nicolas, J.-L., 2006. Cellular and molecular hemocyte responses of the Pacific oyster, Crassostrea gigas, following bacterial infection with Vibrio aestuarianus strain 01/32. Microbes Infect. 8, 27152724.

Le Roux, F., Gay, M., Lambert, C., Waechter, M., Poubalanne, S., Chollet, B., Nicolas, J.-L., Berthe, F., 2002. Comparative analysis of Vibrio splendidus-related strains isolated during Crassostrea gigas mortality events. Aquat. Living Resour. 15, 251-258.

Le Roux, F., Wegner, K.M., Polz, M.F., 2016. Oysters and Vibrios as a model for disease dynamics in wild animals. Trends Microbiol. 24, 568-580.

Lee, J.-W., Nam, J.-H., Kim, Y.-H., Lee, K.-H., Lee, D.-H., 2008. Bacterial communities in the initial stage of marine biofilm formation on artificial surfaces. J. Microbiol. 46, 174182.

Lemire, A., Goudenege, D., Versigny, T., Petton, B., Calteau, A., Labreuche, Y., Le Roux, F., 2015. Populations, not clones, are the unit of vibrio pathogenesis in naturally infected oysters. ISME J. 9, 1523.

Liénart, C., Savoye, N., Bozec, Y., Breton, E., Conan, P., David, V., Feunteun, E., Grangeré, K., Kerhervé, P., Lebreton, B., Lefebvre, S., L’Helguen, S., Mousseau, L., Raimbault, P., Richard, P., Riera, P., Sauriau, P.-G., Schaal, G., Aubert, F., Aubin, S., Bichon, S., Boinet, C., Bourasseau, L., Bréret, M., Caparros, J., Cariou, T., Charlier, K., Claquin, P., Cornille, V., Corre, A.-M., Costes, L., Crispi, O., Crouvoisier, M., Czamanski, M., Del Amo, Y., Derriennic, H., Dindinaud, F., Durozier, M., Hanquiez, V., Nowaczyk, A., Devesa, J., Ferreira, S., Fornier, M., Garcia, F., Garcia, N., Geslin, S., Grossteffan, E., Gueux, A., Guillaudeau, J., Guillou, G., Joly, O., Lachaussée, N., Lafont, M., Lamoureux, J., Lecuyer, E., Lehodey, J.-P., Lemeille, D., Leroux, C., Macé, E., Maria, E., Pineau, P., Petit, F., Pujo-Pay, M., Rimelin-Maury, P., Sultan, E., 2017. Dynamics of particulate organic matter composition in coastal systems: A spatio-temporal study at multi-systems scale. Prog. Oceanogr. 156, 221-239.

Mahé, F., Rognes, T., Quince, C., de Vargas, C., Dunthorn, M., 2014. Swarm: robust and fast clustering method for amplicon-based studies. PeerJ 2, e593. 
Masó, M., Garcés, E., Pagès, F., Camp, J., 2003. Drifting plastic debris as a potential vector for dispersing Harmful Algal Bloom (HAB) species. Sci. Mar. 67, 107-111.

Mason, O.U., Hazen, T.C., Borglin, S., Chain, P.S., Dubinsky, E.A., Fortney, J.L., Han, J., Holman, H.-Y.N., Hultman, J., Lamendella, R., 2012. Metagenome, metatranscriptome and single-cell sequencing reveal microbial response to Deepwater Horizon oil spill. ISME J. 6, 1715.

McCormick, A., Hoellein, T.J., Mason, S.A., Schluep, J., Kelly, J.J., 2014. Microplastic is an Abundant and Distinct Microbial Habitat in an Urban River. Environ. Sci. Technol. 48, 11863-11871. https://doi.org/10.1021/es503610r

McCormick, A.R., Hoellein, T.J., London, M.G., Hittie, J., Scott, J.W., Kelly, J.J., 2016. Microplastic in surface waters of urban rivers: concentration, sources, and associated bacterial assemblages. Ecosphere 7.

McMurdie, P.J., Holmes, S., 2013. phyloseq: an R package for reproducible interactive analysis and graphics of microbiome census data. PloS One 8, e61217.

Nealson, K.H., Hastings, J.W., 2006. Quorum sensing on a global scale: massive numbers of bioluminescent bacteria make milky seas. Appl. Environ. Microbiol. 72, 2295-2297.

Oberbeckmann, S., Kreikemeyer, B., Labrenz, M., 2017. Environmental factors support the formation of specific bacterial assemblages on microplastics. Front. Microbiol. 8, 2709.

Oberbeckmann, S., Löder, M.G., Labrenz, M., 2015. Marine microplastic-associated biofilms-a review. Environ. Chem. 12, 551-562.

Oberbeckmann, S., Loeder, M.G., Gerdts, G., Osborn, A.M., 2014. Spatial and seasonal variation in diversity and structure of microbial biofilms on marine plastics in Northern European waters. FEMS Microbiol. Ecol. 90, 478-492.

Oberbeckmann, S., Osborn, A.M., Duhaime, M.B., 2016. Microbes on a bottle: substrate, season and geography influence community composition of microbes colonizing marine plastic debris. PLoS One 11, e0159289.

Petton, B., Bruto, M., James, A., Labreuche, Y., Alunno-Bruscia, M., Le Roux, F., 2015. Crassostrea gigas mortality in France: the usual suspect, a herpes virus, may not be the killer in this polymicrobial opportunistic disease. Front. Microbiol. 6, 686. https://doi.org/10.3389/fmicb.2015.00686

Reisser, J., Shaw, J., Hallegraeff, G., Proietti, M., Barnes, D.K.A., Thums, M., Wilcox, C., Hardesty, B.D., Pattiaratchi, C., 2014. Millimeter-Sized Marine Plastics: A New Pelagic Habitat for Microorganisms and Invertebrates. PLoS ONE 9, e100289. https://doi.org/10.1371/journal.pone.0100289

R Core Team, 2016. R: A language and environment for statistical computing. R Foundation for Statistical Computing, Vienna, Austria.

Rochman, C.M., 2016. Ecologically relevant data are policy-relevant data. Science 352, $1172-1172$. 
Saulnier, D., De Decker, S., Haffner, P., 2009. Real-time PCR assay for rapid detection and quantification of Vibrio aestuarianus in oyster and seawater: a useful tool for epidemiologic studies. J. Microbiol. Methods 77, 191-197.

Saulnier, D., De Decker, S., Tourbiez, D., Travers, M.A., 2017. Development of a duplex Taqman real-time PCR assay for rapid identification of Vibrio splendidus-related and $V$. aestuarianus strains from bacterial cultures. J. Microbiol. Methods 140, 67-69.

Schmidt, V.T., Reveillaud, J., Zettler, E., Mincer, T.J., Murphy, L., Amaral-Zettler, L.A., 2014. Oligotyping reveals community level habitat selection within the genus Vibrio. Front. Microbiol. 5, 563.

Segata, N., Izard, J., Waldron, L., Gevers, D., Miropolsky, L., Garrett, W.S., Huttenhower, C., 2011. Metagenomic biomarker discovery and explanation. Genome Biol. 12, R60.

Ueki, A., Watanabe, M., Ohtaki, Y., Kaku, N., Ueki, K., 2014. Description of Propionispira arcuata sp. nov., isolated from a methanogenic reactor of cattle waste, reclassification of Zymophilus raffinosivorans and Zymophilus paucivorans as Propionispira raffinosivorans comb. nov. and Propionispira paucivorans comb. nov. and emended description of the genus Propionispira. Int. J. Syst. Evol. Microbiol. 64, 3571-3577. https://doi.org/10.1099/ijs.0.063875-0

Van Sebille, E., Wilcox, C., Lebreton, L., Maximenko, N., Hardesty, B.D., Van Franeker, J.A., Eriksen, M., Siegel, D., Galgani, F., Law, K.L., 2015. A global inventory of small floating plastic debris. Environ. Res. Lett. 10, 124006.

Viršek, M.K., Lovšin, M.N., Koren, Š., Kržan, A., Peterlin, M., 2017. Microplastics as a vector for the transport of the bacterial fish pathogen species Aeromonas salmonicida. Mar. Pollut. Bull. 125, 301-309. 


\section{Tables}

Table 1. Description of the microplastic pools used for bacterial communities analysis. Each pool contained $\mathrm{n}=20$ fragments in the $1-0.3 \mathrm{~mm}$ range, 8 for the $2-1 \mathrm{~mm}$ range, and 4 for the $5-2 \mathrm{~mm}$ range. The pooling rate was adapted to each size class to ensure the recovery of enough DNA quantity for subsequent extraction and sequencing analyses. The number of pool processed per polymer type and size class was dependent on the number of particles collected and correctly identified by micro-spectrometry Raman. PE: polyethylene, PP: polypropylene, PS: polystyrene.

\begin{tabular}{|c|c|c|c|c|c|c|}
\hline Survey & Station & Polymer & Size class & $\begin{array}{l}\text { Nb MP } \\
\text { per pool }\end{array}$ & $\begin{array}{l}\text { Nb pool } \\
\text { processed }\end{array}$ & $\begin{array}{c}\text { Total nb MP } \\
\text { processed }\end{array}$ \\
\hline \multirow{11}{*}{$\begin{array}{c}\text { October } \\
(n=200 \mathrm{MP})\end{array}$} & \multirow{9}{*}{$\begin{array}{c}\mathrm{A} 1(\mathrm{n}=172 \\
\mathrm{MP})\end{array}$} & \multirow{3}{*}{$\mathrm{PE}$} & $0.3-1 \mathrm{~mm}$ & 20 & 2 & 40 \\
\hline & & & $1-2 \mathrm{~mm}$ & 8 & 4 & 32 \\
\hline & & & $2-5 \mathrm{~mm}$ & 4 & 4 & 16 \\
\hline & & \multirow{3}{*}{ PP } & $0.3-1 \mathrm{~mm}$ & 20 & 1 & 20 \\
\hline & & & $1-2 \mathrm{~mm}$ & 8 & 2 & 16 \\
\hline & & & $2-5 \mathrm{~mm}$ & 4 & 2 & 8 \\
\hline & & \multirow{3}{*}{ PS } & $0.3-1 \mathrm{~mm}$ & 20 & 1 & 20 \\
\hline & & & $1-2 \mathrm{~mm}$ & 8 & 2 & 16 \\
\hline & & & $2-5 \mathrm{~mm}$ & 4 & 1 & 4 \\
\hline & \multirow{2}{*}{ M1 (n=28 MP) } & PE & $1-2 \mathrm{~mm}$ & 8 & 1 & 8 \\
\hline & & PS & $0.3-1 \mathrm{~mm}$ & 20 & 1 & 20 \\
\hline \multirow{11}{*}{$\begin{array}{c}\text { December } \\
(n=264 \\
\text { MP })\end{array}$} & \multirow{9}{*}{$\begin{array}{c}\mathrm{A} 1(\mathrm{n}=252 \\
\mathrm{MP})\end{array}$} & \multirow{3}{*}{ PE } & $0.3-1 \mathrm{~mm}$ & 20 & 4 & 80 \\
\hline & & & $1-2 \mathrm{~mm}$ & 8 & 5 & 40 \\
\hline & & & $2-5 \mathrm{~mm}$ & 4 & 5 & 20 \\
\hline & & \multirow{3}{*}{ PP } & $0.3-1 \mathrm{~mm}$ & 20 & 2 & 40 \\
\hline & & & $1-2 \mathrm{~mm}$ & 8 & 1 & 8 \\
\hline & & & $2-5 \mathrm{~mm}$ & 4 & 2 & 8 \\
\hline & & \multirow{3}{*}{ PS } & $0.3-1 \mathrm{~mm}$ & 20 & 2 & 40 \\
\hline & & & $1-2 \mathrm{~mm}$ & 8 & 1 & 8 \\
\hline & & & $2-5 \mathrm{~mm}$ & 4 & 2 & 8 \\
\hline & \multirow{2}{*}{ M1 (n=12 MP) } & \multirow{2}{*}{ PE } & $5-2 \mathrm{~mm}$ & 4 & 1 & 4 \\
\hline & & & $1-2 \mathrm{~mm}$ & 8 & 1 & 8 \\
\hline
\end{tabular}




\section{Figures}

Figure 1. Map of the Bay of Brest indicating sampling locations A1 and M1 and the main anthropogenic pressures. The red cross indicates the sampling station used for surface water collection for the monitoring of physical, chemical, biogeochemical and biological parameters within the scope of the SOMLIT (Service d'Observation en Milieu LITtoral), the French Coastal Monitoring Network (http://somlit.epoc.u-bordeaux1.fr/fr/).

Figure 2. Shared and specific OTU in all sample types (PE, PP, PS and seawater) in October and December 2015.

Figure 3. nMDS plot comparing OTUs of bacteria in all sample types (PE, PP, PS and seawater) in October and December 2015 (Bray-Curtis dissimilarity index). For interpretation of the references to color in this figure legend, the reader is referred to the web version of this article.

Figure 4. Heatmap of the 20 dominants bacterial families in the different sample types (PE, PP, PS and seawater) at October (A) and December 2015 (B).

Figure 5. Cladogram of LEfSe results according to sample types (microplastics and seawater) for samples collected in October 2015 (A) and December 2015 (B) 
Figure 1.

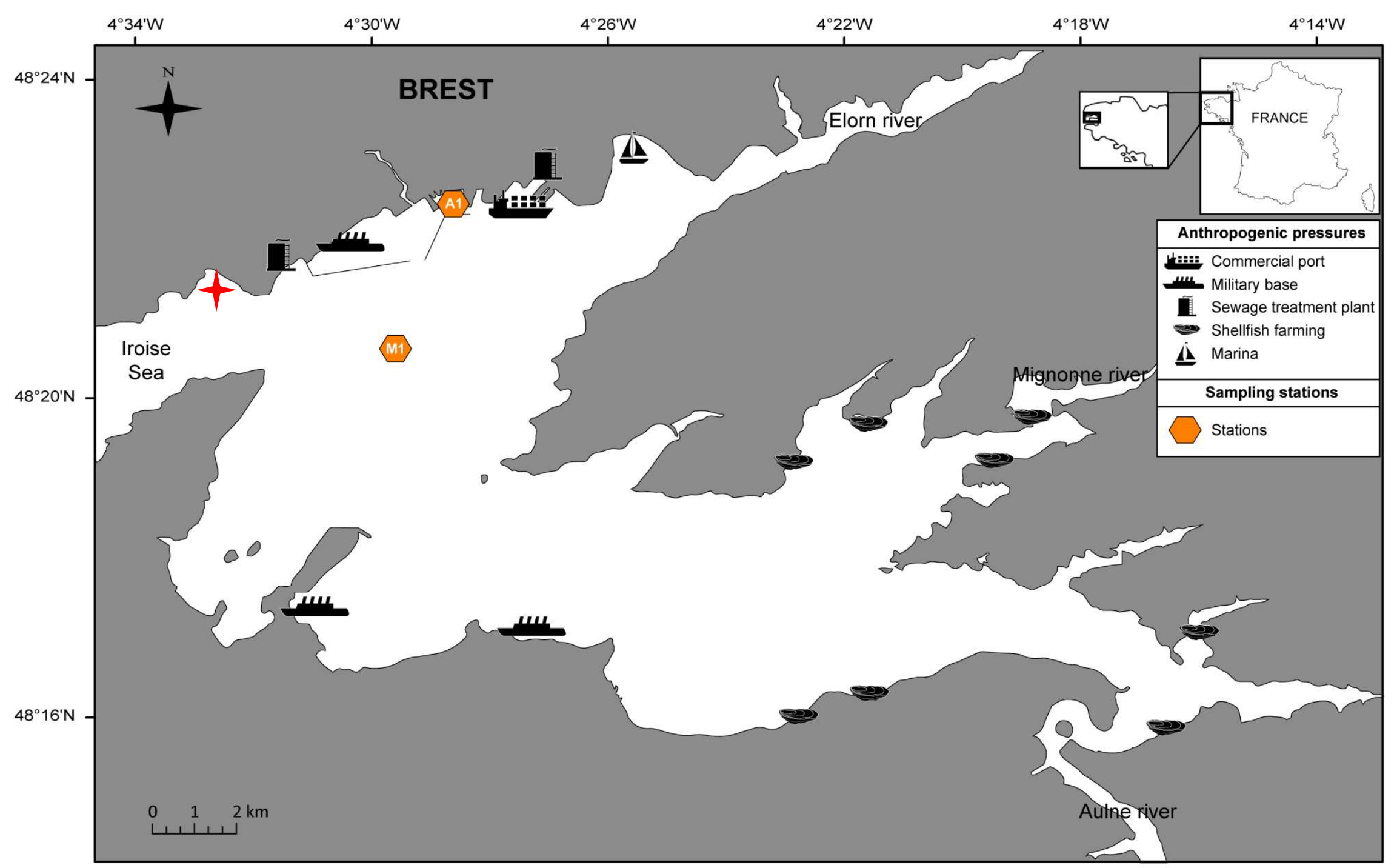


Figure 2
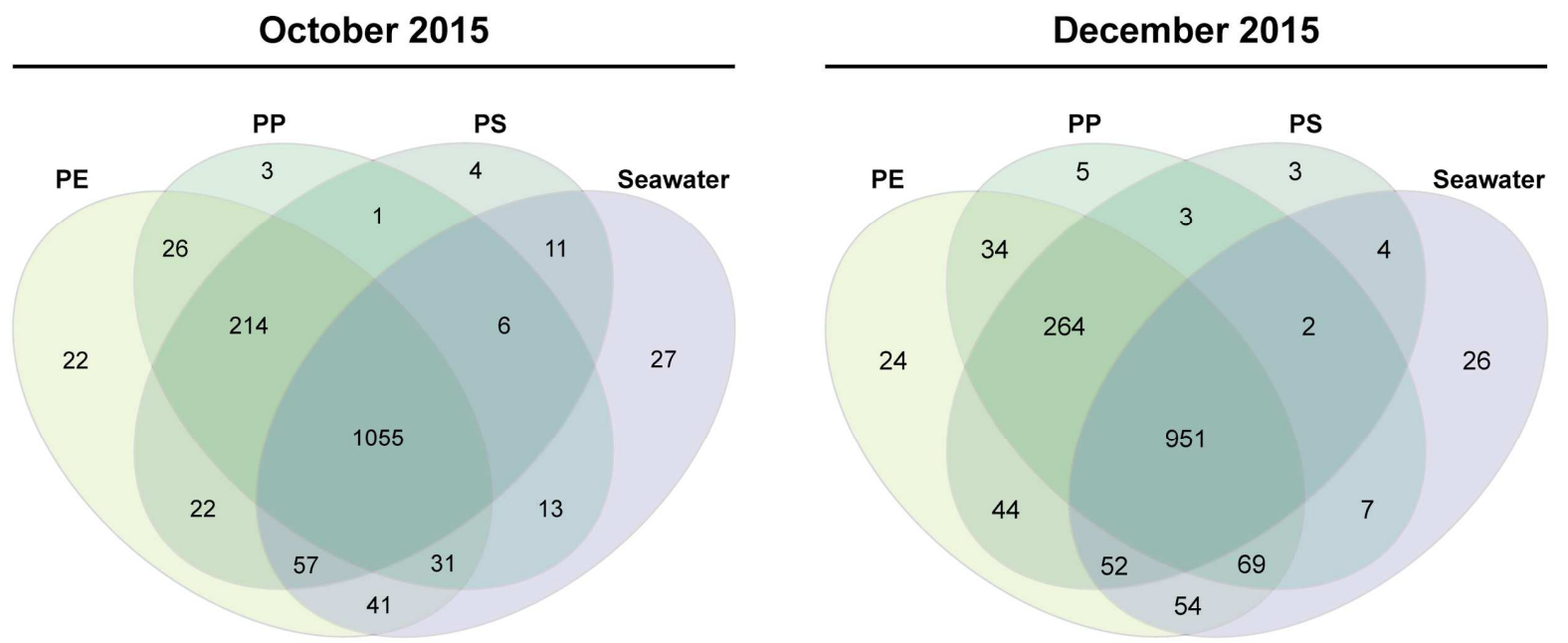
Figure 3

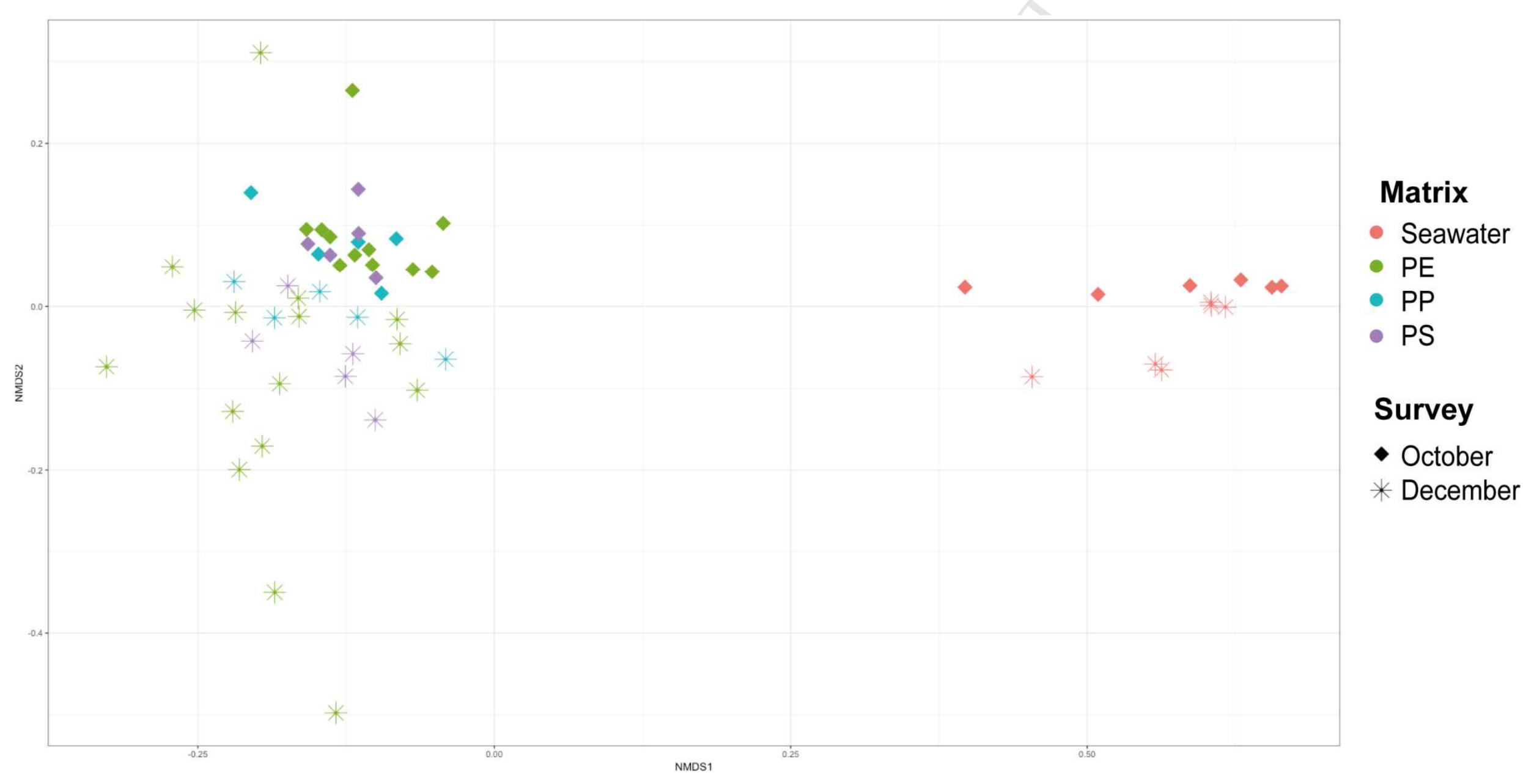


Figure 4

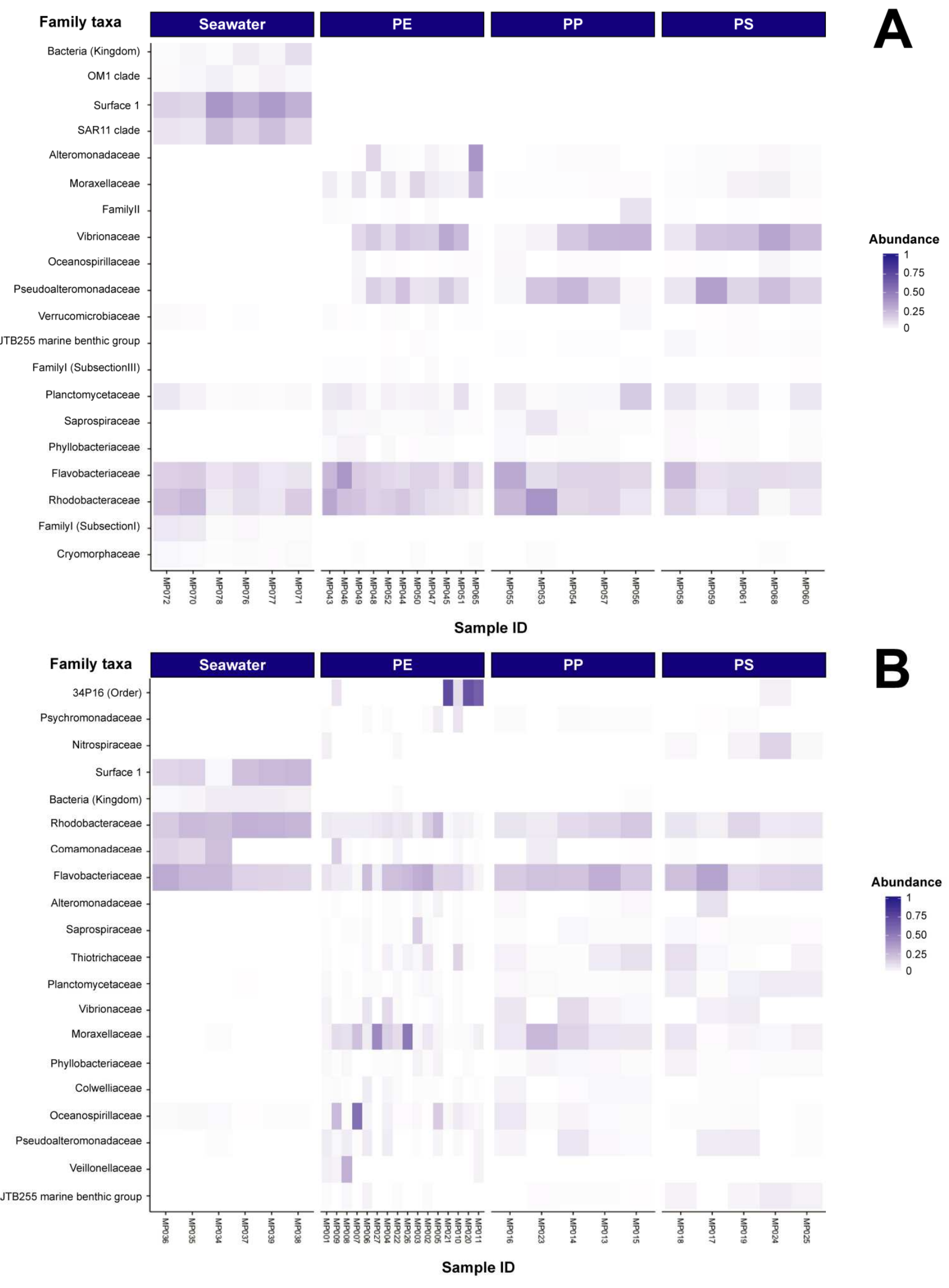




\section{Figure 5}

A

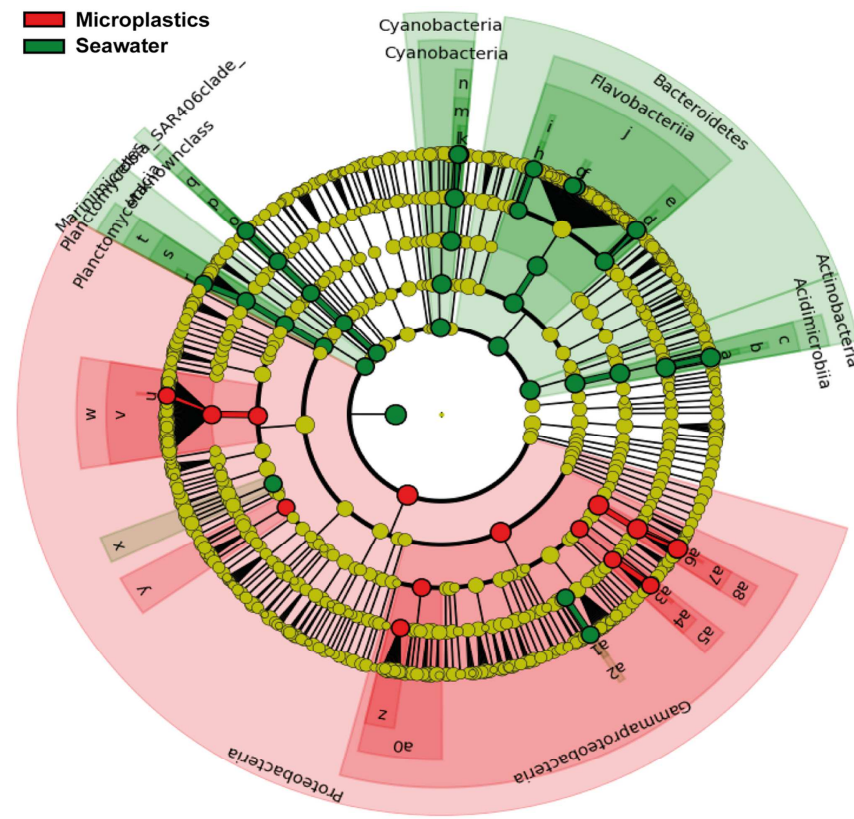

B
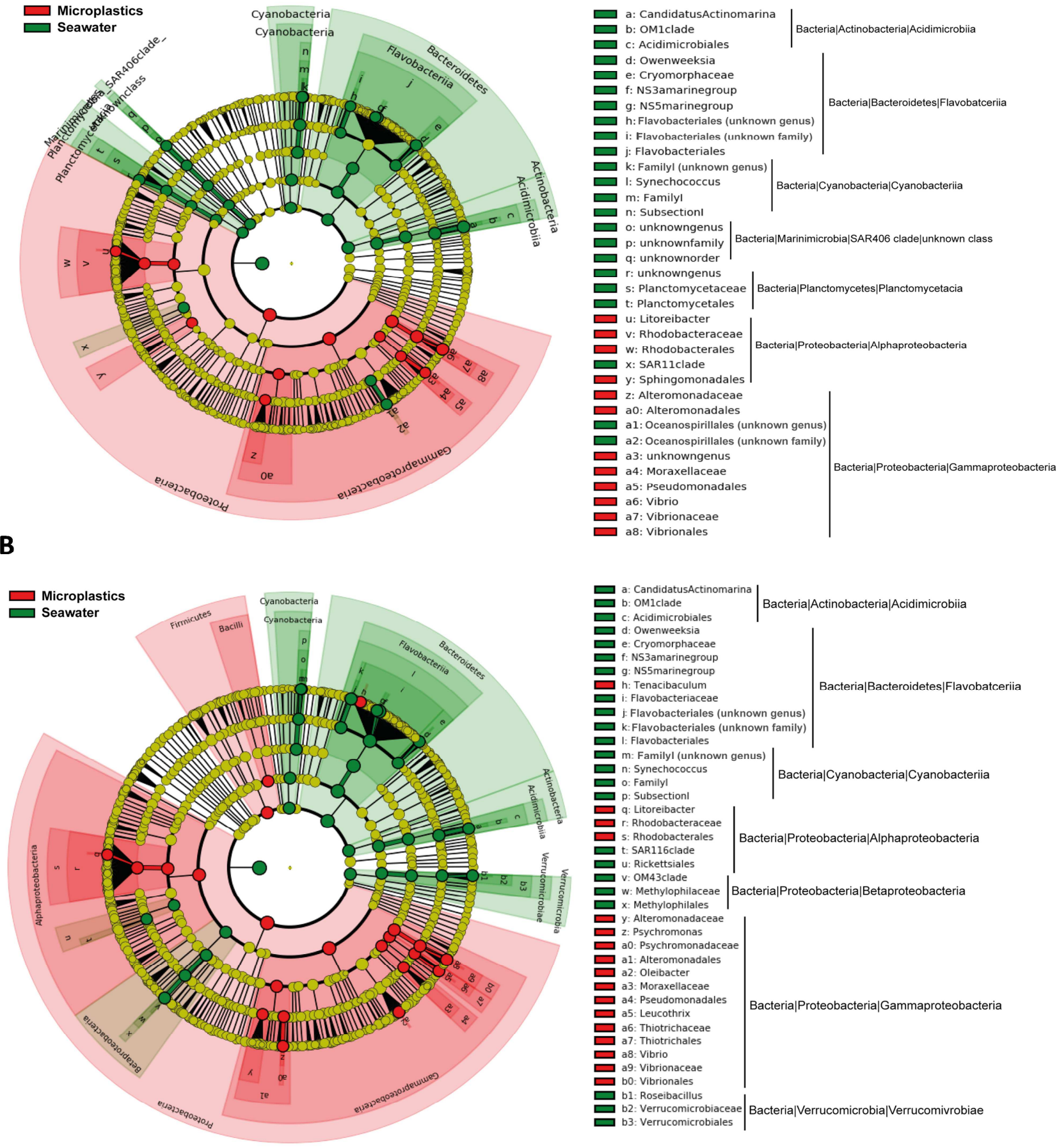